\title{
A COMPARISON OF THE ACCURACY OF THE DISTO-LINGUAL FLANGE ADAPTATION USING TWO DIFFERENT DENTURES BASE MATERIALS IN LOWER COMPLETE DENTURES: AN IN-VITRO STUDY
}

\author{
Nora Mohamed Sheta *
}

\begin{abstract}
Purpose: This study was conducted to compare the adaptation accuracy of distolingual flange of mandibular complete dentures fabricated by versacryl and soft acryl

Material and methods: 14 lower completely edentulous casts with bilateral distolingual undercut were duplicated from mandibular completely edentulous patient.14 Mandibular complete dentures were processed with Conventional heat cure acrylic resin denture base except the distolingual flange. Dentures were divided into two equal groups: Soft acryl Group at the distolingual flange and Versacryl group at the distolingual flange. The gap between the denture and the cast at the distolingual undercut was measured at three points (A,B,C)using Stereo microscope.

Result : The result of this invitro study revealed that median gap width value of soft acryl group (733.2) and IQR 224.65 to median gap width value of Versacryl group (1256.748)and IQR(1039.2) regardless of the location. The Versacryl group showed statistically significant higher median gap width value than soft acryl group with $p$ value $=0.00$

Conclusion : Within the limitation of this invitro study, the gap distance found when using versacryl in the disto lingual undercut, was greater than the gap distance found with the use of soft acrylic. Soft acryl as denture base showed more adaptation comparing to the versacryl as the distolingual flange of in lower complete denture.
\end{abstract}

KEY WORDS: Lower denture, adaptation. Undercut, flexible flange

\section{INTRODUCTION}

The prosthetic treatment of the edentulous patients has always been a challenge for the dentist especially with the mandibular one ${ }^{(1)}$. The most probable cause for this is the smaller denture bearing area, unfavorable distribution of occlusal forces resulting in increased rate of bone resorption, loss of denture stability and retention, pain as well as patient discomfort ${ }^{(2)}$.

* Lecturer, Department of Prosthodontics, Faculty of Dental Medicine, Cairo University. 
The irregular bone resorption may result in the presence of severe undercuts which creates a great problem in completely edentulous patients. However these undercuts may be useful for the retention of the lower denture. ${ }^{(3)}$ Bilateral lingual undercuts in lower edentulous ridge may complicate conventional complete denture construction ${ }^{(4)}$, pre prosthetic surgery can be done to correct this condition. However it is not always possible to use surgical procedures. ${ }^{(5)}$

The rigidity of conventional heat cured acrylic resin has made denture base extension into distolingual undercuts not easy. It is the reason why the use of flexible acrylic resin and resilient denture liners were advocated, to extend deeper into the undercut to gain further retention without harmful effect on the supporting tissues or creating pain and difficulty during denture removal and insertion. ${ }^{(6,7)}$

Denture base adaptation is one of the factors which affect directly the retention and the stability of the complete denture. It is a critical and important factor in a successful complete denture. A clinical study has indicated that well fitted complete denture has been shown to improve nutritional and quality of life outcomes among edentulous patients. ${ }^{(8)}$

The accurate fit of denture base is a main factor in the physical mechanism of complete denture retention ${ }^{(9)}$. Retention of complete denture is directly proportional to the adaptation of the denture base to the supporting oral tissues and retention is maximized when there is more intimate contact with the oral tissues ${ }^{(10)}$.the poorly fitting dentures when subjected to occlusal pressure show more distortion of the mucous membrane and consequent movement of the denture than well-fitting ones. Also, residual ridge resorption may be accelerated due to distor- tion of mucosa and denture movement which occur due to ill-fitting dentures ${ }^{(11)}$

According to literature, and during the last decades, many methods were used to assess adaptation accuracy including using measuring microscope systems, weighing methods, profile projectors and image analysis methods. Reviewing the literature, there was no preference of a method over the other, each method has its advantages and disadvantages ${ }^{(12,13)}$.The aim of this in vitro study is to compare the adaptation accuracy of two different flexible dentures base materials used in the lingual flange to engage bilateral distolingual undercut in lower complete dentures.

\section{MATERIALS AND METHODS}

The sample size calculation was carried by a "power and sample size" program*. Seven dentures for each group were indicated .One completely edentulous patient was selected with mandibular well-developed residual ridge having bilateral distolingual undercuts.

\section{Cast fabrication}

Mandibular primary impression was made for fabrication of complete denture using irreversible hydrocolloid material $^{* *}$ and was poured according to manufacturer's instructions using dental stone ${ }^{* * * *}$. An acrylic special tray was constructed on the study cast. Border molding and final impression was done using a putty and medium addition silicone rubber base impression material ${ }^{* * * *}$ well extended especially at the distolingual area. Boxing and pouring of the secondary impression using extra hard stone to obtain a master cast. (Fig 1) The master cast was duplicated using silicone duplicating material ${ }^{*}$ in a duplicating flask according to the manufacturer's

\footnotetext{
* G*Power program (University of Düsseldorf, Düsseldorf, Germany)

** Zetalgin zermack, Italy

*** TST, Hard stone THS, TAIWAN

**** (Speedex, Coltène/Whaledent Company, Altstätten, Switzerland).medium consistency
} 
instructions. After the silicone hardened the flask was opened and the cast was removed from the silicone mold. Then the silicone mold was cleaned from any remnants then fourteen duplicated casts were poured using extra hard dental stone according to manufactures instruction using vacuum mixer.** The casts were poured all at the same period time in the same room temperature and humidity.

\section{Trial denture base and processed denture con- struction}

A sheet of base plate wax of $1.5 \mathrm{~mm}$ thickness was adapted over one of duplicated cast. The artificial teeth were arranged to obtain an initial trial denture base then it was completely waxed up. Duplication of the outer and the occlusal surfaces of the initial trial denture base was done using silicone duplicating material inside a duplicating flask, fourteen duplicated trial denture base with same artificial teeth size and arrangement were duplicated .Softened base plate wax was placed in the denture base area of the mold then the cast was repositioned in the mold. Excess molten wax escaped then the duplicating flask with the cast was immersed in cold water until the wax hardened. The cast was then removed from the mold and the trial denture was finished. ${ }^{(12)}$

Total fourteen wax dentures on working casts were prepared for this study. The wax dentures with their respective master casts were divided randomly into two equal groups: Soft acryl group and Versacryl group

In both group complete dentures were processed using conventional compression molding technique. (flasking, wax elimination).
Polymethylmethacrylate ${ }^{* * *}$ material was mixed at a polymer: monomer ratio of $3: 1$ by volume. Once the acrylic resin reached the dough stage, it was packed in the flask then the flask was opened and the same area of the lingual flange of the previously packed acryl was removed. In the first group it was replaced by soft acryl ${ }^{* * * * *}$ while in the second group, it was replaced by versacryl ${ }^{* * * * *}$. After that all the tested denture were processed in the curing unit for $90 \mathrm{~min}$ at $70^{\circ} \mathrm{C}$ then $30 \mathrm{~min}$ at $100^{\circ} \mathrm{C}$, benchcooled to room temperature for 30 minutes then finally was immersed in cold water for 15 minutes. After deflasking, excess material was trimmed, the dentures were kept on master casts for measuring the adaptation accuracy.

\section{Adaptation accuracy measurement:}

To measure the gap formation of the distolingual denture flange, the tongue space of each cast were removed using vertical cutting machine ${ }^{\#}$ with diamond disc (2800-3800 revolution/min) under water coolant. A soft tooth brush with a surfactant solution and pressurized air were used to clean the interface area from debris to facilitate accurate measurements. (Fig. 3 a)

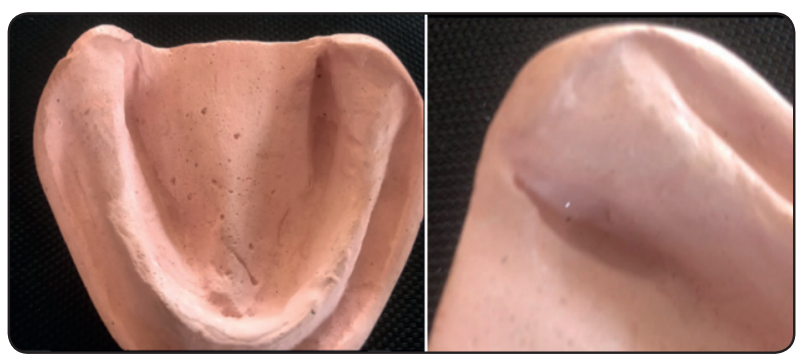

Fig. (1) Lower edentulous cast with bilateral distolingual undercut

\footnotetext{
* Silicone duplicating material (U-402, Nissin, Kyoto, Japan)

** Motovava SL vacuum mixer us dental depot BEGO Germany

*** Vertex regular, Zeist, Netherlands

$* * * *$ Vertex soft-Dental B.V., Zeist, the Netherlands)

***** Versacryl" (Keystone Industries GmbH, Sigen, Germany)

\# BU2Ob-L, automatic feed bench lathe, bengbu, china
} 


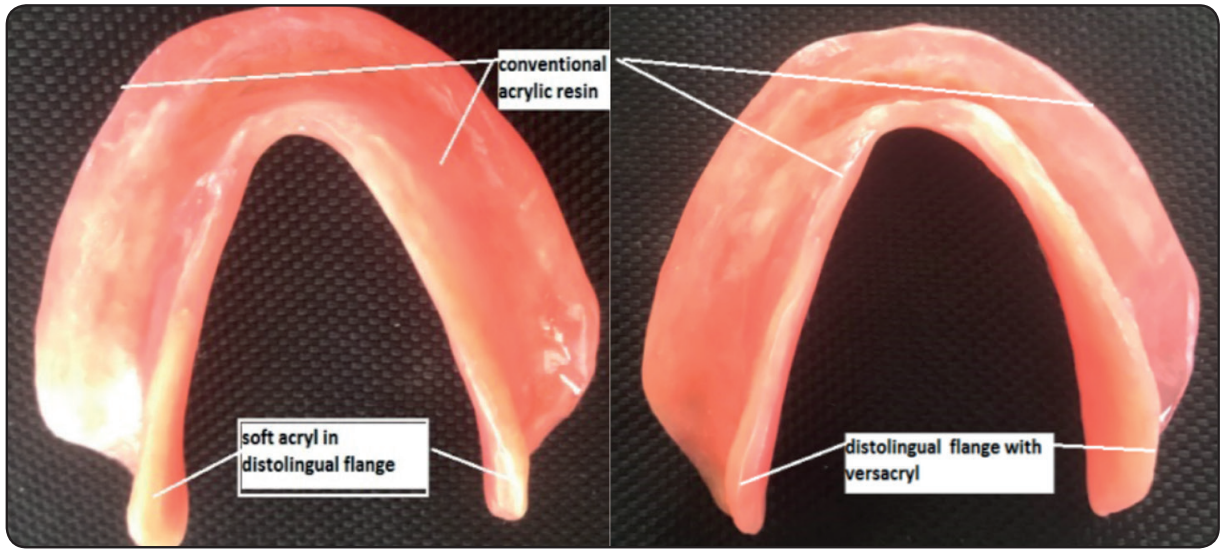

Fig. (2) The finished conventional heat cure acrylic resin denture with soft acryl and versacryl extended into the distolingual undercut

Gap measurement locations were marked as follow: A straight line was drawing starting over the molars central grooves till the end of posterior border of the denture. Three parallels lines was drawing perpendicular to the straight line. The first line referred to the distal surface of the last standing molar (A).The second was $3 \mathrm{~mm}$ posterior to the first line (B) a while the third line was $3 \mathrm{~mm}$ posterior to the second line $(\mathrm{C})$. In each side the three points was marked bilaterally. (Fig3 b) The measurements were done using a zoom stereomicroscope* with 3.0 megapixel CCD cameras** at a $\times 125$ PC-monitor
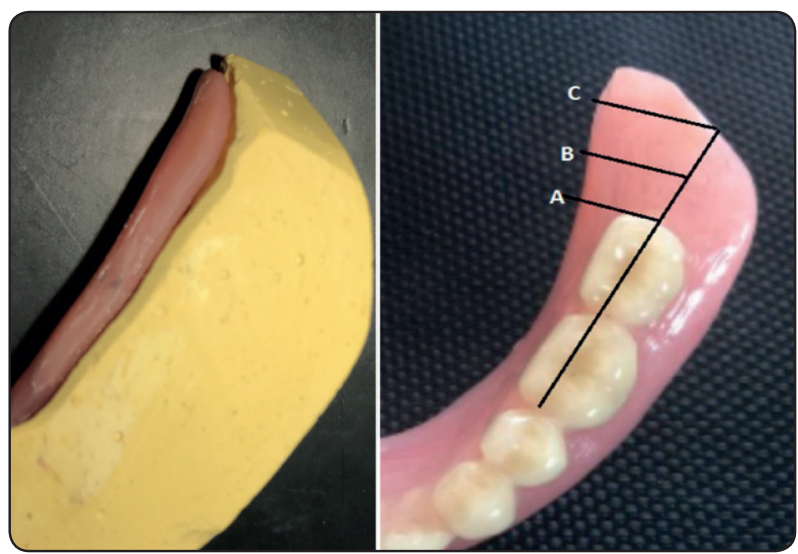

Fig. (3) a) the cast with remove tongue space b) The three reverences point for gap measurement magnification. Calibrated image software (Motic Images plus 2.0) (lesica software) was used to measure the maximum border gap in micrometres resolution at the three point $\mathrm{A}, \mathrm{B}$ and $\mathrm{C}$.

The gap width at each location was measured three times. Then the value A was calculated from the mean of gap width values of both right and left side $A=(A 1+A 2) / 2$. The same measurement was repeated for point B and C.(Fig 4) the examiner who measured the samples under the microscope did not know which material was tested as the two material are the same colour (single blinding)

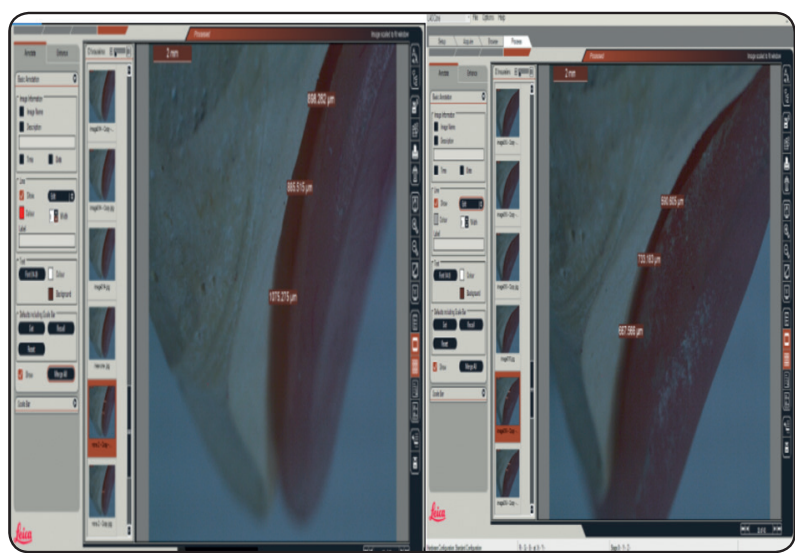

Fig. (4) Examples of Calibrated image lesica software used to measure the gaps by stereomicroscope.

** (SMZ-1500, Nikon, Tokyo, Japan)

*** (Moticam 2300, Motic, Hong Kong) 


\section{Statistical Analysis}

Quantitative data were explored for normality by checking the data distribution and using ShapiroWilk tests. Gap width data showed non-parametric distribution. Data were presented as median, and interquartile range (IQR) Man- Whitney $U$ test was used to compare between the two denture groups

The Kruskal-Wallis $\mathrm{H}$ test was used to compare between the different locations. The significance level was set at $\mathrm{P} \leq 0.05$. Statistical analysis was performed using the SPSS Statistics software Version 13.0: SPSS Inc.

\section{RESULT}

When comparing gap width values of the two studied groups at each location, A , B and C in Versacryl group showed statistically significant higher median gap width values than location A, B and $\mathrm{C}$ in Soft acryl group with significant $\mathrm{P}$ value $=0.002,0.003$ and 0.002 respectively as descripted in table 1

TABLE (1) The median $(\mu \mathrm{m})$, and interquartile range (IQR) for comparing between gap width values of the two studied groups at each location

\begin{tabular}{|c|c|c|c|c|c|}
\hline \multirow[b]{2}{*}{ Location } & \multicolumn{2}{|l|}{ Group I } & \multicolumn{2}{|l|}{ Group II } & \multirow[t]{2}{*}{$P$-value } \\
\hline & Median & IQR & Median & IQR & \\
\hline A & 617.89 & 217.7 & 1080.203 & 793 & $0.002^{*}$ \\
\hline B & 775.321 & 257.5 & 1256.748 & 1108.8 & $0.003^{*}$ \\
\hline $\mathrm{C}$ & 808.023 & 211.2 & 1783 & 1498.6 & $0.002^{*}$ \\
\hline
\end{tabular}

When comparing median gap width values in $\boldsymbol{\mu} \mathbf{m}$ of soft acryl group (733.2) and IQR 224.65 to median gap width value of Versacryl group (1256.748) and IQR(1039.2) regardless of the location the Versacryl group showed statistically significant higher median gap width value than soft acryl group with $p$ value $=0.00$ as shown in figure 5

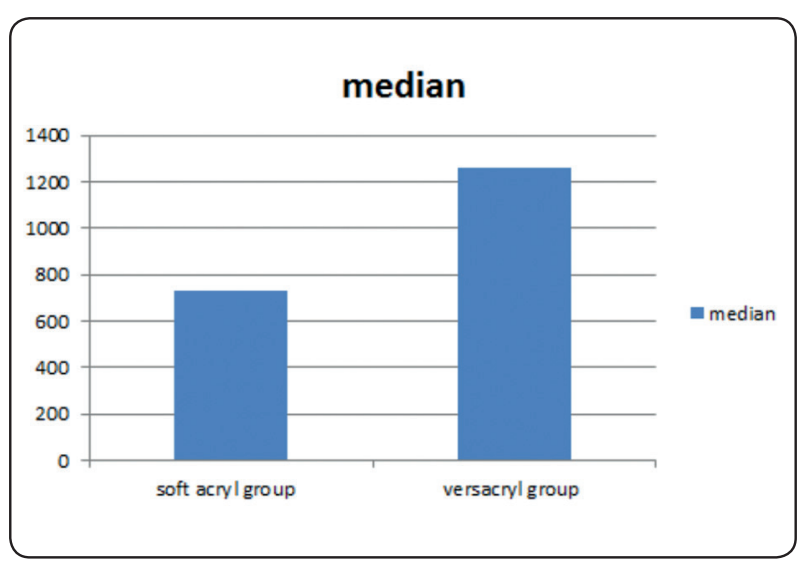

Fig. (5) Bar chart representing median gap width values in $\mu \mathrm{m}$ in both groups regardless of location.

TABLE (2) The median $(\mu \mathrm{m})$, and interquartile range (IQR) for comparing between gap width values of the two groups at each location

\begin{tabular}{|l|l|l|l|l|l|}
\hline & & $\mathrm{A}$ & $\mathrm{B}$ & $\mathrm{C}$ & $P$-value \\
\hline \multirow{2}{*}{$\begin{array}{l}\text { Group } \\
\text { I }\end{array}$} & Median & 617.896 & 775.321 & 808.023 & \multirow{2}{*}{0.149} \\
\cline { 2 - 5 } & IQR & 217.703 & 257.512 & 211.19 & \\
\hline \multirow{2}{*}{$\begin{array}{l}\text { Group } \\
\text { II }\end{array}$} & Median & 1080.203 & 1256.748 & 1783 & \multirow{2}{*}{0.199} \\
\cline { 2 - 5 } & IQR & 793.03 & 1108.76 & 1498.59 & \\
\hline
\end{tabular}

In both groups, the greatest median gap width value was recorded for location $\mathrm{C}$ (the most posterior location) followed by location $\mathrm{B}$ (buccal) then location A (the most anterior location).No statistical significant difference was found between location $\mathrm{A}, \mathrm{B}$ and $\mathrm{C}$ on both groups with $\mathrm{p}$ value $=0.149$ and 0.199

\section{DISCUSSION}

The impaired bearing area of lower edentulous residual ridge makes the retention and stability of complete denture difficult ${ }^{(2)}$. The presence of lingual undercut can improve the retention of complete denture, the engagement of the distolingual undercut increases the mechanical mean of retention in the lower denture as well as the well fitted denture into undercut area increase the physical mean of retention ${ }^{(14)}$ 
The presence of bilateral distolingual undercut improves the retention however it may complicate the path of insertion of the prosthesis it also cause patient discomfort and pain during insertion and removal of the denture when hard acrylic denture base where used. The soft acryl or versacryl lingual flange can be used in such situation as they are semi-rigid flanges that slid easily into the undercut and maximizing the border seal to ensure retention ${ }^{(4)}$

In this study, the presences of the teeth over the denture base have a great influence on the adaptation accuracy of the denture base as reported by other studies ${ }^{(15-17)}$. It was reported that the absence of teeth leads to less denture base distortion and consequently more adaptation and dimensional accuracy that subsequently might affect the results ${ }^{(15)}$. Adaptation accuracy measurement was done before denture-cast separation to avoid release of internal stresses which was reported to occur during deflasking and denture separation leading to great amount of distortion ${ }^{(18)}$. Conventional heat cured acrylic resin is the most used material in the denture base as it is rigid and allow equal force distribution on the supporting structure. The compression molding technique was selected as it was widely used and traditional technique and not need special equipment as the injected molding technique (19) $^{(19)}$

In this invitro study, the distolingual flange of the conventional heat cured acrylic resin was removed after packing and replaced once by soft acryl and once by versacryl as the two materials bond chemically to acrylic resin and they are processed with the same curing cycle of the conventional heat cured acryl. ${ }^{(20-22)}$ on the other hand ,the other flexible thermoplastic denture base material are injected with injection mold technic with $222^{\circ} \mathrm{C}$ so when it is use in combination with conventional heat cured acrylic resin it causes its distortion.

A study was reported that the lower complete denture retention was improved when flexible lingual flanges compared to conventional acrylic resin flanges. The cause may be due to close adaptation to the supporting tissues and effective engagement with the lingual undercut ${ }^{(23)}$

In this study, the changes in the gap width were not even across the selected reference point in the two groups. The greatest gap width value was recorded for the most posterior location with no statistical significance difference This might be attributed as a result of the linear shrinkage and pulling effect of the material. ${ }^{(24.25)}$

In this study the Versacryl group showed statistically significant higher median gap width value than soft acryl group which means that the soft acryl exhibit more adapted denture base when comparing to the versacryl

The versacryl is a thermoplastic material as it must be immersed in warm water $\left(50^{\circ} \mathrm{C}\right)$ for 5 min to be flexible. When placed and adapted to the undercut in the patient mouth it will cool to the body temperature and become rigid to fulfill its function ${ }^{(20)}$, it may be the cause for the prescence of greater gap in the Verscacryl group. However this material are mainly used to construct the lingual flanges of the mandibular complete dentures to engage bilateral undercut it has a number of disadvantages (26.27) and may lose the desired flexibility in the long term.

The soft acryl is considered as permanent heat cured resilient liner as it is perfect for patients who cannot tolerate hard denture bases due to irregular bony ridge and presence of undercuts ${ }^{(28,29)}$ Regarding the oral health related quality of life, it has been found to have a positive impact on the perceived oral health of edentulous patient. Recently it can be used in implant supported overdenture to improve masticatory muscle activity thus improving the patient Satisfaction ${ }^{(30)}$ general consensus that exact adaptation is the key to proper retention of complete dentures and to achieve that, the gap between oral tissue and the denture base should be as small as possible. ${ }^{(9.12)}$ 


\section{CONCLUSION}

Within the limitations of this invitro study, the gap distance found when using Versacryl in the disto lingual undercut, was greater than the gap distance found with the use of soft acrylic when used as a lingual flange to engage distolingual undercut. . Soft acryl as denture base showed more adaptation comparing to the versacryl as the distolingual flange of in lower complete denture.

\section{RECOMMENDATION}

Further studies are still needed focusing on adaptation accuracy of flexible denture base.

\section{REFERENCES}

1. Adell R, Eriksson B, Lekholm U, Brånemark PI, Jemt T. Long-term follow-up study of osseointegrated implants in the treatment of totally edentulous jaws. Int J Oral Maxillofac Implants. 1990; 5 (4):347-359.

2. Awad MA, Lund JP, Dufresne E, Feine JS. Comparing the efficacy of mandibular implant-retained overdentures and conventional dentures among middle-aged edentulous patients: satisfaction and functional assessment. Int J Prosthodont. 2003 Apr; 16(2):117-122.

3. Ghayda'a H. Al-Izzi ,Sabah S. Al-Habib . Percentage of undercut areas in edentulous patients. J Bagh Coll Dent. 2006 ;18 (2): 22-24.

4. Sheen J Arora Aman Arora Anika Kolhar .Rigid undercut, flexible solution int $\mathrm{J}$ of clinical cases and investigation 2015 april 6(3)1-7

5. Virag Srivastava, Laxman Singh ,Devendra, Abhishek . Gum fit denture an alternative to alveoloplasty. Journal of Dental Sciences \& Oral Rehabilitation. 2011 Oct-Dec; 4:51-2.

6. Soni A. Management of severe undercuts in fabrication of complete dentures. N Y State Dent J. 1994;60:36-9. [PubMed]

7. Rickman LJ, Padipatvuthikul P, Satterthwaite JD. Contemporary denture base resins: Part 2. (1802). Dent Update. 2012;39:176-8. 184 [PubMed]

8. Ghani F, Kikuchi M, Lynch C, Watanabe M. Effect of some curing methods on acrylic maxillary denture base fit. Eur J Prostho Rest Dent 2010;18:132-8.
9. Darvell BW, Clark RKF. The physical mechanisms of complete denture retention. Br Dent J 2000; 189:248-52.

10. Sekar V, Sendhilnathan D, Lakshmi S, Abraham A. "A comparative evaluation of palatal adaptation in denture bases processed with compression molding and injection molding in two different palatal configuration"-An In Vitro Study. Int J Sci Res Publ 2015; 5:2250-3153.

11. Rendell J, Grasso JE, Gay T. Retention and stability of the maxillary denture during function. J Prosthet Dent 1995; 73:344-7.

12. Lee C, Bok S, Bae J. Comparative adaptation accuracy of acrylic denture bases evaluated by two different methods. Dent Mater J 2010; 29:411-7.

13. Pavan S, Arioli JN, Santos PH, Mollo FD. Effect of microwave treatments on dimensional accuracy of maxillary acrylic resin denture base. Braz Dent J 2005; 16:119-23.

14. Bocage M, Lehrhaupt J. Lingual flange design in complete dentures. J Prosthet Dent. 1977;37:499-506.[PubMed]

15. Baemmert RJ, Lang BR, Barco MT, Jr., Billy EJ. Effects of denture teeth on the dimensional accuracy of acrylic resin denture bases. Int J Prosthodont 1990; 3: 528-537.

16. Jackson AD, Lang BR, Wang RF. The influence of teeth on denture base processing accuracy. Int J Prosthodont 1993; 6: 333-340

17. Barco MT Jr, Moore BK, Swartz ML, Boone ME, Dykema RW, Phillips RW. The effect of relining on the accuracy and stability of maxillary complete dentures--an in vitro and in vivo study. J Prosthet Dent 1979; 42: 17-22.

18. Parvizi A, Lindquist T, Schneider R, Williamson D, Boyer D, Dawson D V. Comparison of the dimensional accuracy of injection-molded denture base materials to that of conventional pressure-pack acrylic resin. J Prosthodont 2004;13:83-9.

19. Zarb GA, Bolender CL, Carlsson GE. Boucher's prosthodontic treatment for edentulous patients. 11th ed. St Louis: Mosby; 1997. p. 337-42

20. Abrams S A Technique for Using Maxillary Anterior SoftTissue Undercuts in Denture Placement :A Case Report J Can Dent Assoc 2002; 68(5):301-4

21. Keystone Industries. [Last accessed on 2015 July 31]. Available from:https://keystoneind.wordpress.com/tag/ versacryl/

22. Vertex dental www.vertex-dental.com/en/products/18en/26/147-vertex-soft 
23. Singh JP, Dhiman RK, Bedi RP, Girish SH. Flexible denture base material: A viable alternative to conventional acrylic denture base material. Contemp Clin Dent. 2011; 2:313-7.

24. Laughlin GA, Eick JD, Glaros AG, Young L, Moore DJ. A comparison of palatal adaptation in acrylic resin denture bases using conventional and anchored polymerization techniques. J. Prosthodont.2001; 10:204-11.

25. Sanders JL, Levin B, Reitz P V. operative Dentistry Comparison of the adaptation of acrylic resin cured by microwave energy and conventional water bath. Quintessence Int (Berl) 1991;22:181-6.

26. Sunitha NS, Jagadeesh KN, Kalavathi SD, Kashinath KR. "Flexible dentures" - An alternate for rigid dentures? J Dent Sci Res. 2010;1:74-9.
27. Sharma A, Shashidhara HS. A review: Flexible removable partial dentures. J Dent Med Sci. 2014;13:58-62.

28. Lowe LG. Flexible denture flanges for patients who exhibited undercut tuberosities and reduced width of the buccal vestibule: a clinical report. J Prosthet Dent. 2004 Aug; 92(2):128-31.

29. Abrams S, Hellen W. Fabrication of an overdenture which could cover a torus palatinus by using a combination of denture base materials: a case report. Dent Today. 2006 Apr;25(4):74, 76-7.

30. Sultan M, Aboul Elaa A \& Salloumi M. Impact of Thermoplastic Acrylic Denture Base Versus Conventional Base on the Patient Satisfaction in Implant Supported Mandibular Overdenture: A Systematic Review :Indian J of Sci and Tech. 2016 9(45):980-985 